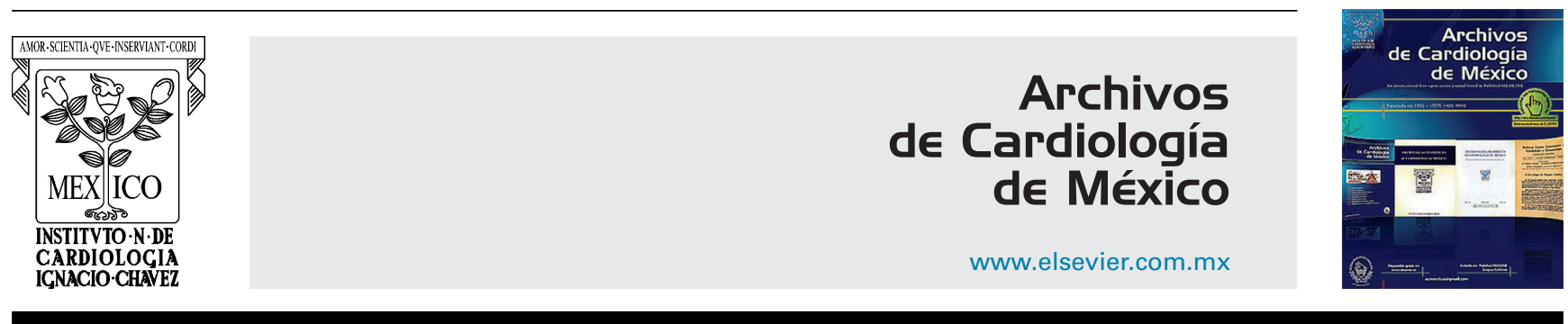

IMAGEN EN CARDIOLOGÍA

\title{
Ictus isquémicos: ¿es obligatorio descartar trombosis aórtica?
}

\section{Ischemic strokes: Is it mandatory to rule out aortic thrombosis?}

\section{Leydimar Anmad Shihadeh ${ }^{\mathrm{a}, *}$, Diego Fernández-Rodríguez ${ }^{\mathrm{a}, \mathrm{b}}$, Antonio Trugeda-Padilla ${ }^{\mathrm{a}}$ y Julio Hernández-Afonso ${ }^{a}$}

\author{
a Servicio de Cardiología, Hospital Universitario Nuestra Señora de Candelaria (Universidad de La Laguna), Santa Cruz de \\ Tenerife, España \\ b Servicio de Cardiología, Hospital Universitario Arnau de Vilanova, Lleida, España
}

Recibido el 8 de septiembre de 2016; aceptado el 16 de enero de 2017

La ateromatosis aórtica es un factor predictor de recurrencia de accidentes cerebrovasculares, especialmente en presencia de placas de gran tamaño o complicadas. Sin embargo, su influencia en la génesis de los ictus isquémicos está infraestimada ${ }^{1,2}$, probablemente debido al escaso porcentaje de pacientes que son sometidos a procedimientos diagnósticos que evalúen la aorta en la práctica habitual ${ }^{2}$. A continuación presentamos un caso de ictus isquémico, en el que un estudio exhaustivo condujo al diagnóstico de una trombosis masiva del arco aórtico.

Una mujer de 77 años hipertensa, diabética, dislipidémica y con antecedentes de ictus isquémicos de repetición ingresó en nuestra institución por hemiparesia izquierda de tiempo de evolución incierto. La tomografía computarizada craneal objetivó un área hipodensa parietal derecha sugestiva de ictus isquémico (fig. 1). Dado el tiempo de evolución

\footnotetext{
* Autor para correspondencia. Carretera del Rosario 145, Santa Cruz de Tenerife, España. Código Postal: 38010.

Correo electrónico: Leydimar_12@hotmail.com (L. Anmad Shihadeh).
}

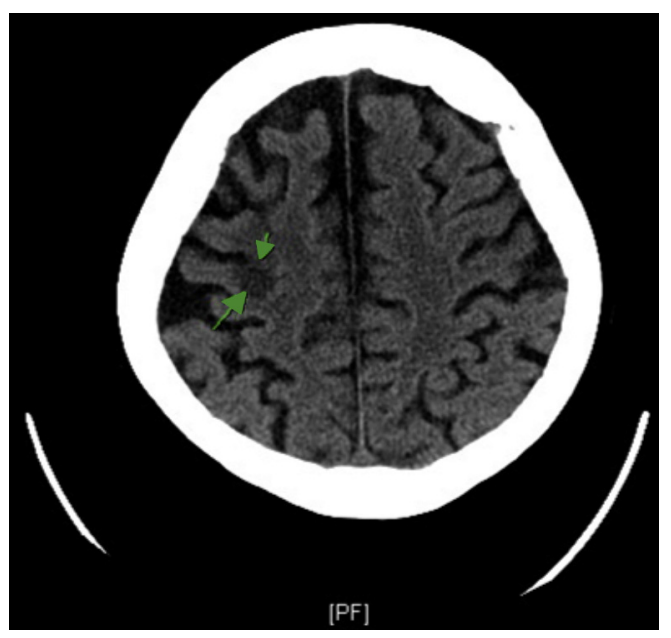

Figura 1 La tomografía computarizada craneal. Se objetivó un área hipodensa parietal derecha sugestiva de ictus isquémico (flecha). 


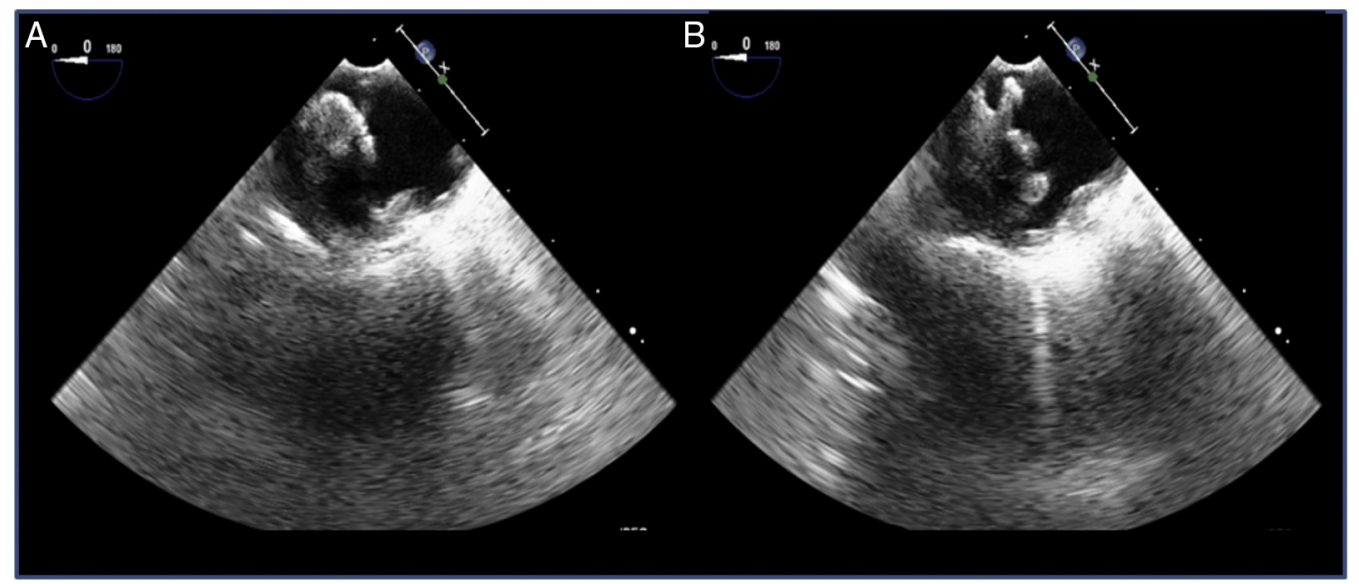

Figura 2 A y B: ecocardiograma transesofágico. En aorta ascendente se observan algunas placas ateroscleróticas. Se observa trombo de $2 \times 1.2 \mathrm{~mm}$ sobre placa aterosclerótica a nivel del final del cayado aórtico a $15-20 \mathrm{~cm}$ de la arcada dentaria. El trombo tiene varias excrecencias, alguna muy móvil.
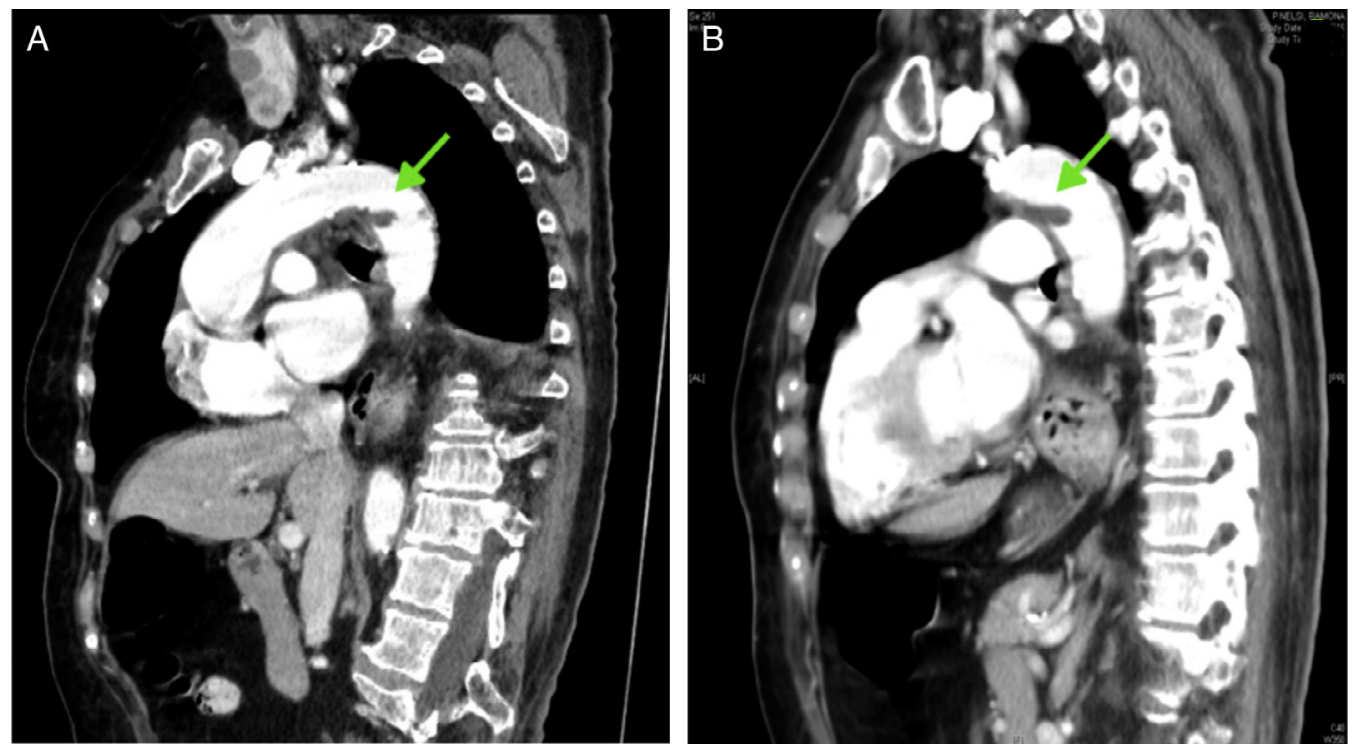

Figura 3 A y B: tomografía computarizada torácica. Muestra imagen circular que corresponde a restos de trombo a nivel aórtico, porción final del cayado aórtico cercano a la salida de la subclavia izquierda y donde no se aprecia trombo a nivel de aorta ascendente.

y las características del cuadro se decidió manejo conservador. El electrocardiograma no objetivó arritmias y la ecocardiografía transtorácica no detectó cardiopatía estructural ni imágenes sugestivas de trombo. La ecografía Doppler demostró ateromatosis carotídea sin estenosis significativas.

A pesar de la importante carga vascular de la paciente se decidió realizar un ecocardiograma transesofágico para ampliar el estudio de tromboembolia. No se detectaron focos embolígenos cardiacos pero se objetivó una trombosis masiva con segmentos móviles a nivel del arco aórtico (fig. 2A y 2B). Se decidió tratamiento antitrombótico intensivo con acenocumarol y clopidogrel con buena evolución clínica de la paciente. Una posterior tomografía computarizada torácica corroboró una reducción de la trombosis aórtica (fig. $3 \mathrm{~A}$ y $3 \mathrm{~B}$ ). A los 3 meses, la paciente continúa asintomática.

En conclusión, incluso en pacientes con carga vascular relevante la exploración de la aorta mediante técnicas de imagen específica ${ }^{2}$ se hace obligatoria en el estudio etiológico del ictus isquémico.

\section{Responsabilidades éticas}

Protección de personas y animales. Los autores declaran que para esta investigación no se han realizado experimentos en seres humanos ni en animales.

Confidencialidad de los datos. Los autores declaran que han seguido los protocolos de su centro de trabajo sobre la publicación de datos de pacientes.

Derecho a la privacidad y consentimiento informado. LoS autores declaran que en este artículo no aparecen datos de pacientes. 


\section{Bibliografía}

1. Cañadas V, Vilacosta I, Luaces M, et al. Trombosis en aorta torácica aparentemente normal y embolias arteriales. Rev Esp Cardiol. 2008;61:196-200.
2. Ringleb PA, Bousser MG, Ford G. Guidelines for management of ischaemic stroke and transient ischaemic attack 2008. Cerebrovasc Dis. 2008;25:457-507. 